\title{
Aa. Vv., «Arthurian Literature», 30
}

\section{Maria Colombo Timelli}

\section{(2) OpenEdition}

\section{Journals}

\section{Édition électronique}

URL : http://journals.openedition.org/studifrancesi/1091

DOI : 10.4000/studifrancesi.1091

ISSN : 2427-5856

\section{Éditeur}

Rosenberg \& Sellier

\section{Édition imprimée}

Date de publication : 1 novembre 2014

Pagination : 571

ISSN : 0039-2944

\section{Référence électronique}

Maria Colombo Timelli, «Aa. Vv., «Arthurian Literature», 30 », Studi Francesi [En ligne], 174 (LVIII | III) |

2014, mis en ligne le 01 novembre 2014, consulté le 18 septembre 2020. URL : http://

journals.openedition.org/studifrancesi/1091 ; DOI : https://doi.org/10.4000/studifrancesi.1091

Ce document a été généré automatiquement le 18 septembre 2020.

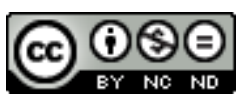

Studi Francesi è distribuita con Licenza Creative Commons Attribuzione - Non commerciale - Non opere derivate 4.0 Internazionale. 


\title{
Aa. Vv., «Arthurian Literature», 30
}

\author{
Maria Colombo Timelli
}

\section{RÉFÉRENCE}

«Arthurian Literature», 30, 2013.

1 Cette issue de la revue américaine d'études arthuriennes contient quatre contributions qui concernent nos études.

2 Les deux premières portent sur Perceforest, dont la date de composition demeure controversée. Richard BARBER apporte sa pierre à l'édifice: à ses yeux, plusieurs éléments concourent à situer la rédaction du roman autour de 1345, au moment où Édouard III fit construire le bâtiment destiné à accueillir la Table Ronde (Edward III's Arthurian Enthusiasms Revisited: 'Perceforest' in the Context of Philippa of Hainaut and the Round Table Feast of 1344, pp. 55-74). Nigel BRYANT s'interroge en revanche sur le rapport entre les dieux païens et la présence de Dieu dans le roman: dans un monde où les deux croyances semblent pouvoir coexister - à l'intérieur d'un système que l'on pourrait définir 'féodal' - l'homme doit lui aussi assumer un rôle, incarné par la prouesse chevaleresque (Pagan Gods and the Coming of Christianity in 'Perceforest', pp. 75-85).

Un corpus arthurien 'tardif' fait l'objet de deux autres articles.

4 Carol J. CHASE, 'Transmuer de rime en prose': The Transformation of Chrétien de Troyes's Joie de la Cour Episode in the Burgundian Prose 'Erec' (1450-1460), pp. 101-115. La lecture en parallèle de la Joie de la Cour dans les vers de Chrétien et dans la prose anonyme du Xve siècle révèle non seulement des ajustements sur le plan quantitatif (le prosateur tend dans l'ensemble à abréger sa source, sans que cette pratique soit régulière tout au long du texte), mais surtout la volonté de rationaliser le modèle: en particulier, l'auteur bourguignon supprime les divergences entre le récit que Mabonagrein fait à Erec et celui que son amie propose à Enide, et surtout - par le mariage qui conclut l'épisode - il rend leur aventure finalement acceptable et leur intégration sociale possible. 
5 Patricia VICTORIN, La rétro-écriture ou l'écriture de la nostalgie dans le roman arthurien tardif: 'Ysaïe le Triste', 'Le Conte du Papegau' et 'Mélyador' de Froissart, pp. 117-139. Ces trois romans arthuriens - deux en prose, le troisième en vers - constituent un terrain privilégié pour examiner l'«écriture de la nostalgie» qui semble caractériser la fin du $X_{V}{ }^{e}$ et le début $d u X V^{e}$ siècle. Au-delà des remarques sur les caractères propres de chaque texte, P.V. essaie une approche originale en appliquant à Ysaïe, Papegau, Mélyador, les catégories du rétro-marketing élaborées par Stephen Brown: celles-ci permettraient de mieux comprendre les «besoins d'un lectorat en mal d'Arthur et d'arthurianisme» (p. 135), et par là les réponses que deux auteurs anonymes d'une part, et Froissart de l'autre, se sont efforcés d'offrir, chacun à sa manière et avec des résultats différents. 